\title{
ОСНОВНЫЕ ФАКТОРЫ, ДЕТЕРМИНИРУЮЩИЕ ПРЕСТУПЛЕНИЯ ПРОТИВ ОБЩЕСТВЕННОЙ НРАВСТВЕННОСТИ
}

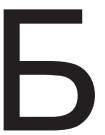

ольшинство ученых признают, что фракторы преступности - явление (совокупность явлений), воздействующее на преступность (порождающее, способствующее или препятствующее ей) ${ }^{1}$.

В нашем исследовании криминогенных фракторов, способствующих рассматриваемой категории преступлений, мы исходили из следующих теоретических посылок.

1. В большинстве случаев невозможно четко разграничить явления, собственно порождающие данные преступления, и явления, способствующие распространению (росту) уголовно наказуемых деяний. Мы разделяем высказанное в литературе мнение о том, что оценка одних явлений в качестве причин, а других в качестве условий носит относительный характер. Конкретное явление в одних взаимодействиях может играть роль причины, в других - условия ${ }^{2}$. В этой связи в исследовании целесообразно использовать понятие криминогенного фактора, которое охватывает как явления, порождающие преступления против общественной нравственности, так и способствующие их распространению или росту их общественной опасности.

2. Несмотря на значительное число научно оправданных классификаций факторов преступности и ее отдельных видов, современная исследовательская практика достаточно убедительно свидетельствует в пользу объединения групп однородных по своей природе причин и условий пре-

\footnotetext{
${ }^{1}$ Криминология: Словарь / Под общ. ред. С.П. Сальникова. - СПб. 1999. - С. 178.

${ }^{2}$ Криминология / Под общей ред. А.И. Долговой. - М., 1997. - C. 216.
}

ступности в факторные (причинные) комплексы на основе критерия обособленной сфреры социальной жизни, к которой преимущественно относятся соответствующие группы фракторов: экономические, правовые, духовно-нравственные, социальнопсихологические, организационные и др.

Как показывают результаты выполненного автором исследования, а также выводы других исследователей, именно эти группы криминогенных факторов требуют наибольшего внимания правоохранительных органов.

Среди социально-экономических детерминант преступности против общественной нравственности, можно указать на неудовлетворительное экономическое положение отдельных социальных групп населения (низкий уровень материального обеспечения отдельных слоев населения, существующая в стране безработица, особенно среди женщин и др.).

По мнению большинства опрошенных экспертов (сотрудников ОВД), данный причинный комплекс является ведущим в детерминации проституции и связанной с ней преступности. По результатам проведенного диссертантом опроса сотрудников органов внутренних дел, среди основных социально-экономических предпосылок криминального рынка сексуальных услуг (этот рынок в основном женский) названы: низкий уровень дохода, в том числе молодежи $(18,6 \%)$; стремление женщин к «красивой» и «беспечной» жизни, «легкому» заработку $(58,2 \%)$; безработица среди женщин $(13,6 \%)$, легкость заработка в сорере оборота сексуальных услуг (12,5\%), ограниченное число социально приемлемых спосо- 
бов обеспечения женщинам желаемого ими высокого уровня жизни (11,8\%).

Не имея возможности законным путем удовлетворять свои материальные потребности, отдельные молодые женщины начинают «делать деньги» и добывать необходимые вещи и продукты в меру своих сил и возможностей, в том числе путем оказания сексуальных услуг.

К сказанному следует добавить, что незанятость несовершеннолетних, создающая потенциальную угрозу вовлечения их в сексуальные отношения с совершеннолетними лицами, в том числе в изготовление порнографических изображений.

Социально-экономические противоречия в общественной жизни привели к изменению нравственных стереотипов сознания населения, утрате культурных ориентиров, распаду традиционных ценностей.

Применительно к рассматриваемой группе преступлений нравственный аспект состоит в том, что у девушек и женщин, соглашающихся прямо или косвенно на эксплуатацию в сексуальном смысле велика деградация духовности. И этому есть основания, поскольку современное общество недостаточно укрепляет устоев для женственности, семейности и материнства.

Среди духовно-нравственные детерминант преступности, сопряженной с проституцией, опрошенные в ходе исследования сотрудники ОВД, отметили такие явления, как низкий уровень морально-нравственных ценностей населения $(12,7 \%)$; переориентация молодежи с коллективистских духовных ценностей на корыстно-индивидуалистические $(13,6 \%)$, нравственная деградация $(5,8 \% \%)$.

Специалисты, занимающиеся изучением отношений полов, отмечают в последние годы существенное снижение возрастных границ начала сексуальных контактов. В сорере развлечений, как результат ослабления запретов против наготы, получают распространение так называемые эротические шоу, стриптиз-программы.

Среди факторов, усугубляющих проблему борьбы с преступлениями против общественной нравственности, следует выделить негативные последствия миграции. Причем интенсивная миграция отмечается не только среди взрослых, но и среди несовершеннолетних, что подтверждается сведениями центров временной изоляции для несовершеннолетних правонарушителей органов внутренних дел. Около 10\% несовершеннолетних, поступающих в такие центры, являются жителями стран-участниц Содружества независимых государств. Девушки, проживающие в государствах-участниках Содружества, прибывают в Россию в поисках работы, и, не найдя ее, пополняют ряды проституток. Объектом повышенного интереса дельцов секс-бизнеса становятся иногородние девушки, сбежавшие из дома. Эта категория женщин также чаще всего подвергается сексуальной эксплуатации.

К аналогичным выводам приходят и другие исследователи. Так, в ходе проведенного А.М. Нурмухаметовой опроса лиц, занимающихся проституцией, установлено, что $7 \%$ из них являются гражданами иностранных государств, еще $20 \%$ - приезжие из других субъектов Российской Федерации, а 39\% - приезжие из других населенных пунктов данного субъекта Российской Федерации ${ }^{3}$.

Комментируя приведенные данные, следует отметить, что отсутствие экономических возможностей вне г. Москвы и в окружающих восточно-европейских странах, в комбинации с предположением о том, что в г. Москве имеется большое количество экономических возможностей, ведет к постоянному миграционному потоку людей

\footnotetext{
${ }^{3}$ См.: Нурмухаметова. А. М. Уголовная ответственность за преступления, связанные с проституцией, и их предупреждение: Автореф. дис. ... канд. юрид. наук. - Н. Новгород, 2012. - C. 17.
} 


\section{Полицейская деятельность 2 • 2014}

в Москву. Эта мигрирующая, временная популяция мужчин, создает значительную потребность в сексуальных услугах. Одновременно, молодые женщины, которые не могут найти работу в местах своего постоянного проживания, также ищут возможности найти работу в г. Москве, что приводит к притоку молодых женщин в г. Москву, которые затем начинают заниматься коммерческим сексом. Миграция привела к появлению процветающей индустрии в районах за г. Москвой, которая специализируется в вербовке молодых женщин для работы в коммерческом сексе в г. Москве.

К числу важнейших фракторов, способствующих совершению рассматриваемых преступлений, можно отмети коммерциализацию сексуальных отношений, крайне высокую доходность преступлений, связанных с проституцией и порнобизнесом.

Вовлечение женщин к занятиям проституцией, организация занятия проституцией, торговля людьми с целью сексуальной эксплуатации, порнобизнес являются высокоприбыльными преступлениями, сопровождаются минимальным риском по сравнению с торговлей наркотиками и оружием. При этом извлеченные доходы уходят в теневую экономику и затем отмываются в различных легальных сферах: через торговые сети, банки и т.д.

По оценкам экспертов, международная торговля девушками и молодыми женщинами из бывшего Советского Союза для целей сексуальной эксплуатации - это организованный преступный бизнес с многомиллиардными доходами. Ежегодный оборот в сфрере торговли женщинами как живым товаром для нужд секс-индустрии оценивается, по разным оценкам, в 7-12 миллиардов долларов ${ }^{4}$.

Имеющиеся цифры можно рассматривать как примерно рисующие картину ситу-

\footnotetext{
${ }^{4}$ См.: Торговля людьми из России и стран СНГ / http://www. angelcoalition.org/drupal/node $/ 8$
}

ации, но следует всегда помнить и учитывать, что реальные, теневые цифры могут во много раз превосходить официальные.

Вместе с тем следует обратить внимание, что немаловажную роль в механизме преступлений, связанных с проституцией, играет личность «клиента» - потребителя сексуальных услуг. По мнению ряда специалистов, и автор придерживается этой позиции, именно постоянный спрос на данную услугу позволяет процветать этому виду криминального бизнеса. Среди лиц, покупающих данную услугу, оказывающих "стимулирующее» воздействие на состояние преступности в сфере сексуальной эксплуатации, можно выделить социальную группу представителей «богатого меньшинства», характеризующихся в целом высоким (престижным) социальным статусом, высоким уровнем материальных доходов и высокими потребительскими стандартами. В данную группу входят высокопоставленные сотрудники министерств и ведомств, бизнесмены, предприниматели и иные лица, процветающие при рыночной экономике.

Основной социальной детерминантой организованной преступности, связанной с проституцией, являются недостатки в семейной сфере. Отсутствие должной поддержки со стороны государства института семьи и детства, главным образом, скоординированной социальной работы с неблагополучными семьями; неполная семья, плохие взаимоотношения между членами семьи, применение насилия, отсутствие контроля за детьми и др. все это вместе взятое толкает определенную категорию, в том числе несовершеннолетних к занятию проституцией, в том числе в ее организованных формах.

Обострение проблем семейного неблагополучия на общем фоне постоянной нужды, моральная и социальная деградация, происходящая в семьях, приводят к крайне негативным последствиям. Известно, что в 
основном в этих семьях процветают пьянство, наркомания, половая распущенность среди женщин, проституция, отсутствуют какие-либо нравственные устои, элементарная культура.

Специфика причинного комплекса преступлений, связанных с оборотом порнографических материалов или предметов, состоит в том, что он фоормируется на фроне общих криминальных факторов под непосредственным влияние причин и условий, характерных для организованной, корыстной и сексуальной преступности, что отражает взаимосвязь порнографии с организованным криминальным рынком. Спрос и предложение на порнографическую продукцию формируется под влиянием разложения нравственных и духовных устоев общества, кризиса воспитательного потенциала семьи и других институтов социализации личности, неудовлетворительного социально-экономического положения большей части населения, психофизических и психосоциальных особенностей отдельных индивидов, способствующих формированию девиантных фрорм поведения в сфрере сексуальных отношений.

В качестве фактора, оказывающего влияние на преступность, связанную с изготовлением и оборотом материалов или предметов с порнографическими изображениями, в том числе несовершеннолетних в сети «Интернет», следует отметить технологические факторы, связанные с функционированием сети "Интернет».

Анализ показывает, что сеть «Интернет» в настоящее время представляет собой одно из наиболее развивающихся и эфрфективных средств телекоммуникации современной цивилизации. Однако в последнее время технологические возможности сети умело используют представители криминального сообщества как средство совершения самых разнообразных преступлений, число которых растет пропорционально росту темпов освоения Интернет-технологий.
К технологической группе фракторов следует отнести технологические особенности сети «Интернет», не позволяющие в полной мере осуществлять контроль за информационными потоками и фильтрацию информации порнографического содержания (масштабность аудитории Интернет-пользователей, виртуальность границ киберпространства глобальной сети, анонимность, повсеместное использование электронных платежей за предоставленные услуги и т.д.). Кроме того, во избежание ответственности российские распространители данного контента размещают серверы с порнографической продукцией за пределами России на информационных ресурсах государств, где это законодательно разрешено.

Активность преступных группировок. Этот фактор является наиболее важным фактором развития организованной проституции, порнобизнеса, а также торговли женщинами с целью сексуальной эксплуатации. Отмеченные выше социально-экономические факторы облегчают преступность в рассматриваемой сорере, но не являются ее причинами. Многие регионы Российской Федерации являются дотационными, но не каждый такой регион становится поставщиком женщин для секс-индустрии. Участники преступных группировок извлекают преимущества из бедности, безработицы и желания заработать, для вовлечения в занятие проституцией, а также вербовки и продажи женщин в секс-индустрию. Без вербовщиков, торговцев и сутенеров, организованная проституция и торговля женщинами с целью сексуальной эксплуатации не существовала бы.

В качестве фрактора, оказывающего влияние на совершение рассматриваемых преступлений, можно указать на недостатки в деятельности правоохранительных органов, на которые возложена борьба с преступлениями против общественной нравственности. 


\section{Полицейская деятельность 2 • 2014}

Проведенное исследование показало, что среди существенных недостатков в деятельности органов внутренних дел по выявлению, предупреждению, раскрытию и расследованию преступлений против преступлений против общественной нравственности необходимо в первую очередь выделить следующие недостатки:

1) недостаточная эфффективность деятельности органов внутренних дел по выявлению преступлений против общественной нравственной нравственности.

Вовлечение в занятие проституцией и организация занятия проституцией, порнобизнес - это профессиональная криминальная деятельность, в которую вовлечено большое количество лиц, она приносит высокую прибыль, характеризуется высокой степенью организованности с распределением ролей, служит почвой для коррупции работников правоохранительных органов, тесно сопряжена с совершением иных преступлений (как правило, сексуальной направленности), иными словами, имеет признаки организованной преступности. Даже если содержатель притона не входит ни в какую организованную группу, тем не менее, он нуждается в помощи соучастников, которые занимаются наймом проституток для работы в притоне.

Вместе с тем, борьба с данными видами преступлений со стороны органов внутренних дел носит пока бессистемный, непоследовательный характер. Выявляются они, как правило, случайно, к уголовной ответственности привлекаются один-два человека, их соучастники и криминальные взаимосвязи в полной мера не выявляются, оперативно-розыскное обеспечение расследования по большинству возбужденных уголовных дел не осуществляется.

Как отмечалось выше, количество выявленных преступлений этого вида не соответствует масштабу их фрактического распространения в стране.

Полагаем, что одной из причин сложившейся ситуации является недооцен- ка общественной опасности этих видов преступлений, если точнее - устаревших взглядов на вовлечение в занятие проституцией и на организацию занятия проституцией как на проявление непрофессиональной, бытовой преступности, что ведет к их высокой латентности. В результате многие сотрудники органов внутренних дел, сомневаясь в судебной перспективе подобных дел, не направляют достаточного количества сил и средств на раскрытие подобных преступлений.

Как показывает анализ практика, в регионах отсутствует комплексный подход к выявлению преступлений, связанных с проституцией, не налажено должное взаимодействие между подразделениями органов внутренних дел. Отсутствует четкое разделение компетенции отдельных служб и подразделений органов внутренних дел, приводящее к тому, что практически за состояние борьбы с данным явлением никто не отвечает.

К уголовной ответственности по ст. 242, 242.1, 242.2 УК РФ в основном привлекаются лица, осуществляющие продажу порнографических материалов или предметов. А вот те, которые осуществляют преступную деятельность, направленную на организацию изготовления таких материалов и предметов, функционирование сети торговли данной продукцией, т.е. лица, занимающиеся организацией этого преступного бизнеса, остаются в тени

Вне сореры деятельности подразделений органов внутренних дел, специализирующихся на борьбе с организованной преступностью, остается выявление преступных связей лиц, занятых изготовлением и оборотом порнографии, пресечение преступной деятельности активно функционирующих в этой сорере устойчивых преступных групп.

Подавляющее большинство преступников, выявленных в связи с незаконным оборотом порнографических материалов, в том числе детской порнографии, - рас- 
пространители. Что же касается главных организаторов порноиндустрии, то они в большинстве своем уходят от ответственности, а потерпевшие от их преступной деятельности несовершеннолетние в течение длительного времени продолжают подвергаться сексуальной эксплуатации.

Выявляются такие преступления, как правило, случайно, к уголовной ответственности привлекаются один - два человека. Их соучастники и криминальные взаимосвязи не устанавливаются. Несмотря на то, что порнобизнес приобретает все более организованный, межрегиональный и транснациональный характер, преступные группы в указанной сфере практически не выявляются.

2) недостаточная эфрфрективность профрилактической работы органов внутренних дел по пресечению и предупреждению преступлений против общественной нравственности.

Наиболее существенным недостатком профилактической работы органов внутренних дел в указанном направлении во многих случаях является ее фрормализм. Ему в большей степени подвержена индивидуальная профилактика, осуществление которой связано с деятельностью, затрагивающей права и интересы граждан, требующей специальных криминологических и правовых знаний, психолого-педагогических навыков. Такими качествами далеко не всегда обладают лица, осуществляющие индивидуальную профилактическую работу. К тому же еще не в полной мере отработан правовой механизм осуществления этой деятельности. Не вполне четко определены правовые основания для начала индивидуальной профилактики, объемы и границы ее проведения.

Участковые уполномоченные полиции зачастую не располагают необходимой для предупреждения указанных преступлений информацией о населении административного участка, характере его занятости, местах концентрации лиц с противоправным поведением, не проводят поквартирные обходы административного участка в целях выявления несовершеннолетних, находящихся в социально опасной ситуации, не заносят полученную информацию для последующего анализа и систематизации.

Проводимые подразделениями территориальных органов внутренних дел мероприятия по противодействию распространению детской порнографии и других фрорм сексуальной эксплуатации несовершеннолетних малоэффективны, страдают формализмом, отсутствием должной координации, выражающейся в отсутствии полного и своевременного обмена информацией.

Следует отметить отсутствие в нарушение Федерального закона от 24 июня 1999 г. «Об основах системы профилактики правонарушений и беспризорности несовершеннолетних» тесного взаимодействия органов внутренних дел с другими субъектами системы профилактики (комиссиями по делам несовершеннолетних и защите их прав, органами образования, здравоохранения и социальной защиты населения) в сфрере выявления детей, вовлеченных в проституцию, порнобизнес, подвергающихся сексуальным посягательствам.

3) недостаточная эфрфективность деятельности органов внутренних дел по раскрытию и расследованию преступлений против общественной нравственной нравственности.

В отдельных случаях фракты преступлений против общественной нравственности расследуются изолированно, без выявления сопряженных с ними других, более тяжких преступлений. Зачастую при расследовании уголовного дела о тяжком преступлении (убийстве, разбое, вымогательстве) становится известно о фрактах содержания притонов для занятия проституцией, которые и создали причины и условия для совершения расследуемого преступления, но меры по расследованию деятельности самих этих притонов не принимаются. 


\section{Полицейская деятельность 2 • 2014}

При расследовании организации занятия проституцией отмечается искусственное ограничение предмета расследования, которое выражается, как правило, в недостаточном понимании того факта, что притонодержательство - это такой вид преступной деятельности, который на сегодняшний день почти всегда носит организованный характер. Стремление ограничить задачи расследования привлечением к ответственности того единственного лица, в отношении которого возбуждено уголовное дело, приводит к процессуальному упрощенчеству, формализму, неполноте расследования, а в конечном итоге - не пресечению преступной деятельности криминальных организаций.

К числу правовых факторов, имеющих криминогенное значение, можно отнести - недостатки, пробелы и изъяны действующего уголовного законодательства.

Говоря о недостатках уголовной ответственности за преступления против общественной нравственности, следует отметить отсутствие законодательного определения понятия «проституция» и ее признаков, понятия «порнографическая продукция», ее основных признаков и отличий от продукции эротического характера; отсутствие законов, регламентирующих и регулирующих оборот порнографической продукции.

Несовершенство законодательной базы по данной категории преступлений создает определенные сложности при доказывании составов преступлений, предусмотренных ст. 240, 241, 242, 242.1, 242.2 УКРФ, и правильной квалификации рассматриваемых деяний.

Таким образом, фракторы, детерминирующие преступления против общественной нравственности, являются достаточно обширными и разноплановыми. Каждая из указанных детерминант представляет собой самостоятельную социальную проблему, требующую решения. При этом данные фракторы взаимозависимы, в связи с чем устранение причин и условий совершения рассматриваемой категории преступлений возможно только при комплексном решении проблем, обозначенных в данной работе.

\section{Библиография:}

1. Криминология: Словарь / Под общ. ред. С.П. Сальникова. - СПб. 1999.

2. Криминология / Под общей ред. А.И. Долговой. - М., 1997.

3. Нурмухаметова. А. М. Уголовная ответственность за преступления, связанные с проституцией, и их предупреждение: Автореф. дис. ... канд. юрид. наук.-Н. Новгород, 2012.

4. Торговля людьми из России и стран СНГ //http://www.angelcoalition.org/drupal/node/8

5. Куракин А.В., Костенников М.В. Административно-правовое противодействие коррупции в системе государственной службы и в деятельности сотрудников полиции Российской Федерации и зарубежных государств // NB: Российское полицейское право. - 2013. - 1. - С. 65 - 83. DOI: 10.7256/2306-4218.2013.1.735. URL: http://www.e-notabene.ru/pm/article_735.html

6. Костенников М.В. К вопросу о противодействии коррупции в полиции // NB: Административное право и практика администрирования. - 2013. - 12. - C. 66 - 73. DOI: 10.7256/23069945.2013.12.10700. URL: http://www.e-notabene.ru/al/article_10700.html

7. Куракин А.В. Административно-правовые аспекты юридической ответственности в механизме противодействия коррупции в системе государственной службы Российской Федерации // NB: Административное право и практика администрирования. - 2013. - 7. - С. 137 - 157. DOI: 10.7256/2306-9945.2013.7.9954. URL: http://www.e-notabene.ru/al/article_9954.html 
8. Астишина Т.В. Взаимосвязь преступлений против общественной нравственности с иными видами преступлений // Полицейская деятельность. - 2014. - 1. - C. 22 - 29. DOI: 10.7256/2222-1964.2014.1.10778.

9. Костенников М.В., Куракин А.В., Калита И.А. Прокуратура и противодействие коррупции // NB: Административное право и практика администрирования. - 2013. - 10. - С. 166 - 186. DOI: 10.7256/2306-9945.2013.10.9929. URL: http://www.e-notabene.ru/al/article_9929.html

10. Куракин А.В. Компетенция полиции в сфере реализации законодательства об административных правонарушениях // NB: Административное право и практика администрирования. - 2013. - 4. - C. 28 - 48. DOI: 10.7256/2306-9945.2013.4.8841. URL: http://www.e-notabene. ru/al/article_8841.html

\section{References (transliteration):}

1. Nurmukhametova. A. M. Ugolovnaya otvetstvennost' za prestupleniya, svyazannye s prostitutsiei, i ikh preduprezhdenie: Avtoref. dis. ... kand. yurid. nauk.-N. Novgorod, 2012.

2. Kurakin A.V., Kostennikov M.V. Administrativno-pravovoe protivodeistvie korruptsii v sisteme gosudarstvennoi sluzhby i v deyatel'nosti sotrudnikov politsii Rossiiskoi Federatsii i zarubezhnykh gosudarstv // NB: Rossiiskoe politseiskoe pravo. - 2013. - 1. - C. 65 - 83. DOI: 10.7256/23064218.2013.1.735. URL: http://www.e-notabene.ru/pm/article_735.html

3. Kostennikov M.V. K voprosu o protivodeistvii korruptsii v politsii // NB: Administrativnoe pravo i praktika administrirovaniya. - 2013. - 12. - C. 66 - 73. DOI: 10.7256/2306-9945.2013.12.10700. URL: http://www.e-notabene.ru/al/article_10700.html

4. Kurakin A.V. Administrativno-pravovye aspekty yuridicheskoi otvetstvennosti v mekhanizme protivodeistviya korruptsii v sisteme gosudarstvennoi sluzhby Rossiiskoi Federatsii // NB: Administrativnoe pravo i praktika administrirovaniya. - 2013. - 7. - C. 137 - 157. DOI: 10.7256/23069945.2013.7.9954. URL: http://www.e-notabene.ru/al/article_9954.html

5. Astishina T.V. Vzaimosvyaz' prestuplenii protiv obshchestvennoi nravstvennosti s inymi vidami prestuplenii // Politseiskaya deyatel'nost'. - 2014. - 1. - C. 22 - 29. DOI: 10.7256/22221964.2014.1.10778.

6. Kostennikov M.V., Kurakin A.V., Kalita I.A. Prokuratura i protivodeistvie korruptsii // NB: Administrativnoe pravo i praktika administrirovaniya. - 2013. - 10. - C. 166 - 186. DOI: 10.7256/23069945.2013.10.9929. URL: http://www.e-notabene.ru/al/article_9929.html

7. Kurakin A.V. Kompetentsiya politsii v sfere realizatsii zakonodatel'stva ob administrativnykh pravonarusheniyakh // NB: Administrativnoe pravo i praktika administrirovaniya. - 2013. - 4. - C. 28 -48. DOI: 10.7256/2306-9945.2013.4.8841. URL: http://www.e-notabene.ru/al/article_8841.html 